\title{
Impact of urban planning alternatives on air quality: URBAIR model application
}

\author{
C. Borrego ${ }^{1}$, P. Cascão ${ }^{1}$, M. Lopes ${ }^{1}$, J. H. Amorim ${ }^{1}$, R. Tavares ${ }^{1}$, \\ V. Rodrigues ${ }^{1}$, J. Martins ${ }^{1}$, A. I. Miranda ${ }^{1} \&$ N. Chrysoulakis ${ }^{2}$ \\ ${ }^{I}$ CESAM \& Department of Environment and Planning, \\ University of Aveiro, Portugal \\ ${ }^{2}$ Foundation for Research and Technology, Hellas, Greece
}

\begin{abstract}
In the last decades, the study of the urban structure impacts on the quality of life and on the environment became a key issue for urban sustainability. Nowadays the relevance of urban planning for the improvement of the interactions between different land uses and economic activities, and also towards a more sustainable urban metabolism, is consensually accepted. A major interest relies on understanding the role of planning on induced mobility patterns and thereafter on air quality, particularly related with the increasing use of private cars. This is one of the main objectives of BRIDGE, a research project funding by the European Commission under the $7^{\text {th }}$ Framework Programme and focused on "SustainaBle uRban plannIng Decision support accountinG for urban mEtabolism".

In this scope, and to evaluate the impact on air quality due to different city planning alternatives (PA), the urban scale air quality modelling system URBAIR was applied to selected areas in Helsinki (Finland), Athens (Greece) and Gliwice (Poland), to estimate traffic related emissions and induced pollutant concentration of different air pollutants, in a hourly basis for the entire year of 2008 .

For the Helsinki study case the results suggest that urban traffic and building placement considered on the different PA have an influence on local air quality despite no significant concentration levels. In the Athens case study some PA induce a decrease on traffic flows with an improvement of the air quality over the domain. On the contrary, other leads to an increase of PM10 in selected hotspots. The simulations for the Gliwice study case show minor changes between the baseline and the PA, since the proposed interventions do not imply major changes in traffic flows.
\end{abstract}


URBAIR applications allowed a comparative analysis between current situation and predefined PA in terms of the number of exceedances to air quality thresholds and other parameters established in European legislation. The results provide important information to urban planners and policy makers to choose the best PA according to quality of life standards pursuit by the local authorities.

Keywords: sustainability, urban planning, air quality modelling, traffic emissions, integrated air quality system, decision support system.

\section{Introduction}

In the last decades the study of the urban structure impacts on the quality of life and on the environment became a key issue for urban sustainability. Several studies recognize the importance of urban planning for the improvement of the interactions between different land uses and economic activities, and also towards a more sustainable urban metabolism [1]. Urban structure (sprawl or compact) is intimately related with urban fluxes (incoming and outgoing) of material, energy, information, people, etc. [2]. A major interest relies on understanding the role of planning on induced mobility patterns and thereafter on air quality, particularly related with the increasing use of private cars [3].

According to the European Environmental Agency [4] most EU Member States still do not comply with the PM10 limit values (for which the attainment year was 2005 according to Directive 1999/30/EC). Especially in urban areas, the exceedance of the daily mean PM10 limit value is not only a compliance problem but also has important potential adverse effects on human health.

The most critical issue for $\mathrm{NO}_{2}$ compliance in European countries is the exceedance of the annual $\mathrm{NO}_{2}$ limit value in urban areas, particularly at measurement stations close to streets [5].

In this context, the current challenge to urban planners and environmental engineers is to reverse the impacts on environment and human health resulting from the problematic cohabitation between intense road traffic and high population densities, as a way to promote a better quality of life to urban populations.

Air quality models proves to be an important tool to assess the impact of urban planning alternatives on traffic patterns, on urban air quality allowing the identification and study of hot spots and helping on the definitions of new urban configurations to improve the quality of life for citizens [6-8]. At the same time, the rapid and continuous growth of hardware capabilities opens a vast number of new possibilities to air quality models, especially through the development of online tools, to be implemented in new Decision Support Systems (DSS).

\section{Methodology}

This work presents the development of the Urban Air Quality system (URBAIR) and its implementation, as an on-line tool, into a multi-purpose DSS for sustainable urban planning. In the core of URBAIR system is a second generation Gaussian model, which has been enhanced with a number of 
functionalities, namely the estimation of road traffic emissions. The model provides air quality patterns for a given spatial domain and time period (usually one year, in compliance with the European Legislation (Directive 2008/50/CE) for different air pollutants, namely: particulate matter with aerodynamic diameter smaller than $10 \mu \mathrm{m}$ (PM10), nitrogen dioxide $\left(\mathrm{NO}_{2}\right)$, sulphur dioxide $\left(\mathrm{SO}_{2}\right)$ and carbon monoxide $(\mathrm{CO})$.

Because of the capability to simulate the effect of buildings geometry on air pollutants dispersion, URBAIR offers the possibility to assess the impact of urban planning strategies and traffic management scenarios on air quality.

\subsection{URBAIR system description}

URBAIR system integrates a set of pre-processors of urban geometry, meteorological information and air pollutants emission data in a single tool specifically developed to run online in a Decision Support System (DSS) build under a GIS platform. The URBAIR structure is organized into 4 modules as schematically shown in figure 1 .

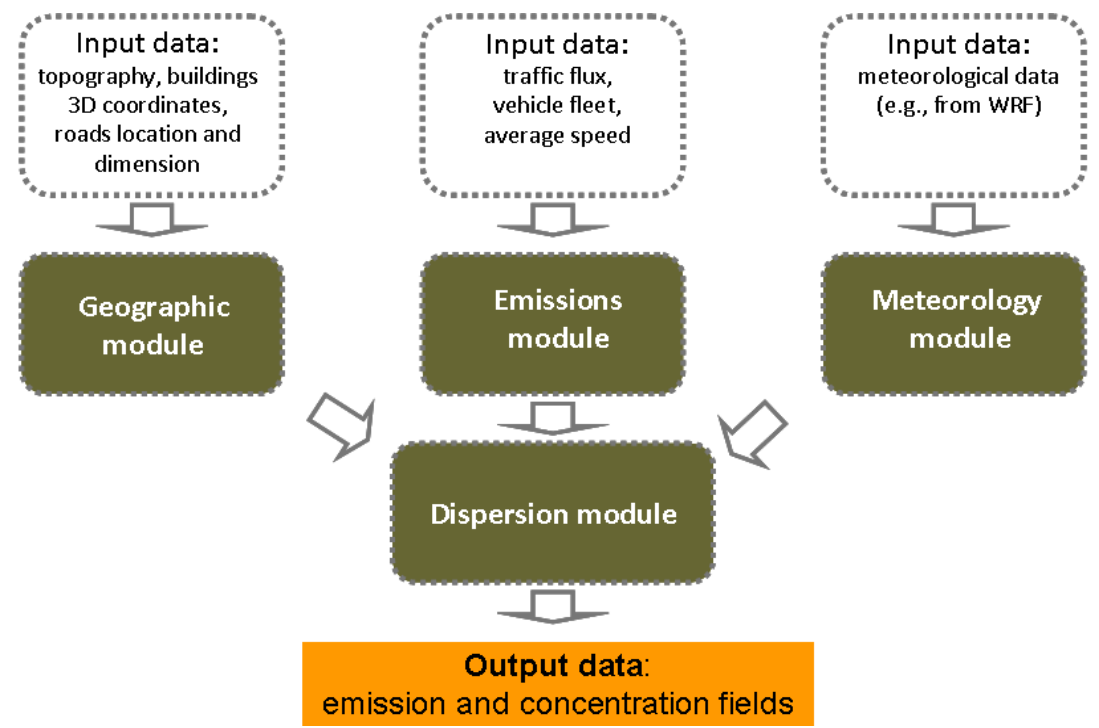

Figure 1: $\quad$ URBAIR system architecture.

The emission module allows the estimation of road traffic emissions using the code of the Transport Emission Model for Line Sources (TREM) [6], which has been integrated into URBAIR. Because topography and build-up structures characteristics have a significant influence on the dispersion of atmospheric pollutants, in particular in urban areas, transport and dispersion of the emitted air pollutants (gaseous and particles) is modelled applying an improved version of the second generation Gaussian model POLARIS [9], which allows to account for the presence of buildings in the dispersion simulation. In this sense, URBAIR 
requires also the characterization of the spatial variation of terrain surface elevation, buildings 3D coordinates and emission sources location and dimensions, which are usually provided by Geographical Information System maps. The geographic module relies on a Cartesian coordinate system, in which regular and discrete gridded data can be used to characterize and spatially distribute terrain, receptors and sources. Representative terrain-influence heights and 'projected' building structures influence are determined following widely used modelling approaches. Topography is specified in the form of terrain heights at receptor locations. The influence of buildings on air pollutants dispersion depends on the orientation of the obstacle relating to the source, the wind direction and the shape of the building.

The meteorological pre-processor calculates the parameters needed by the dispersion model, namely the atmospheric turbulence characteristics, mixing heights, friction velocity, Monin-Obukhov length and surface heat flux. The meteorological data needed for this pre-processing stage can be provided by mesoscale meteorological models, or alternatively surface measurements and upper air soundings databases can be used.

Meteorological information, geographic and geometric data, and road traffic fluxes constitute the major categories of input data needed by the integrated air quality system URBAIR. The output data includes the estimated emissions from road traffic and pollutant concentration at user-specified receptor points or spatially distributed over a regular grid. The first version of URBAIR was designed for line sources since there are the most important ones in urban environments. New model developments include elevated point sources (such as industrial facilities and combustion activities for residential and services sectors). Different mean averaged concentration values can be defined, depending on the evaluation purposes.

\subsection{Study cases description}

URBAIR system was applied to three European urban areas, selected BRIDGE project case studies, with distinct characteristics namely on dimension and planning attributes: Helsinki, Athens, and Gliwice. With the objective of evaluating the impact on air quality due to different city structure design options, different PA were simulated.

The study areas were defined based on detailed information relating the baseline situation and the proposed planning alternatives using ArcGIS maps.

Traffic is considered as the main pollutant source in the study areas. Emissions are calculated by the pre-processor TREM using traffic counts provided by each city and average speeds. In URBAIR roads are spatially discretized by defining an adequate number of point sources along each road. Previous sensibility analysis has demonstrated that a spacing of 10 to 15 meters between adjacent point sources guarantees the needed accuracy in the representation of the roads existing in the domain.

Meteorological input data, including vertical profiles, were obtained from the WRF mesoscale model simulations over the different case studies domains. 
The intervention area in Helsinki is located in the forest area between current housing of Meri-Rastila and Vartiokylä Bay. The planning objectives for this area are: to provide new housing for the growing metropolitan areas; to provide places of work mixed with housing; to deal with demographic polarization; to move towards more owned dwellings and bigger apartments; to improve services; to maintain sufficient and continuous recreation and habitats; and to improve accessibility to nature areas [10].

Three planning alternatives have been proposed with varying combinations of housing density and office space, and differing relative footprints. These alternatives consider three different building configurations with different number of new roads and, consequently, of traffic fluxes.

The URBAIR computational domain, with approximately $4000 \times 4000 \mathrm{~m}^{2}$, and a spatial resolution of $100 \times 100 \mathrm{~m}^{2}$, was defined at the centre of the study area. For the current situation (baseline) the urban built-up area was simplified by considering 234 grouped buildings with different configurations both in geometry and heights. PA1 considers a total of 251 grouped buildings, while in PA2 and PA3, 254 and 263 building blocks, respectively, were defined. All the alternatives imply an increase on the number of roads (see Figure 2).

The Athens case study is focused on the municipality of Egaleo, which lies in the Western part of Athens. Five main road axes divide the area in four quarters. One of the quarters is an industrial degraded area called Brownfield (Figure 3). The total area of Egaleo is 650 ha. The intervention area is centred at the Brownfield industrial area. The computational domain has an area of approximately $4000 \times 4000 \mathrm{~m}^{2}$, with a spatial resolution of $100 \times 100 \mathrm{~m}^{2}$. Built-up geometry was simplified by grouping the existing buildings in 151 blocks. No simulations were carried out for PA1, because no changes in urban planning or traffic are foreseen. PA2 implies an increase in the number of buildings. Traffic fluxes were assumed as identical to nearby roads in the Egaleo area. PA3 considers the conversion of the intervention area into a green zone. Consequently, a reduction of $90 \%$ in traffic in relation to nearby roads was assumed.

Gliwice is a city with an old Town in the central part and residential districts around the centre, with a total area of $134 \mathrm{~km}^{2}$ [6]. The alternatives include: PA1) the construction of a sports hall, which will entail an additional load of people in the area; PA2) the construction of a centre for new technologies, a 7storey building incorporating sustainable energy use (e.g. heat energy from solar collectors, energy recovery, etc.); and PA3) the development of both projects considered in PA1 and PA2. The case study will be mainly assessed with regard to the environmental load in the area (particularly from the point of view of emissions and resource use) and the transport and economic implications to the city.

The URBAIR computational domain, with $5400 \times 5400 \mathrm{~m}^{2}$ and a spatial resolution of $100 \times 100 \mathrm{~m}^{2}$, was centred at the intervention zone. 92 rearranged building blocks were defined in URBAIR for the baseline situation. PA1 and PA2 considers the construction of only one additional building (the sports hall and the centre for new technologies, respectively), while for PA3 both were 
defined in URBAIR (Figure 5). The most significant change is the increase of traffic flows due to foreseen attraction of public.

\section{Air quality results for baseline and planning alternatives}

In Figure 2, PM10 simulation results for Helsinki on $25^{\text {th }}$ July 2008 are presented for baseline situation and PA1, PA2 and PA3.


Figure 2: Comparison of $1.5 \mathrm{~m}$ high horizontal 24 hour average [PM10] fields in Helsinki domain, on $25^{\text {th }}$ July 2008 for: a) baseline, b) PA1, c) PA2 and d) PA3. Red rectangle indicates the intervention area. (See online for colour version.)

Comparing the results observed in Figure 2 it is possible to conclude that despite the changes on the number of roads and respective traffic fluxes, and also on the number and location of buildings, the different alternatives do not induce significant modifications on the dispersion patterns. However, and according to the simulations, PA2 and PA3 have a higher influence over the [PM10] in the intervention area and, particularly in PA3, in an area located to the north of the new buildings and roads. In general, [PM10] over the domain stay within the limit value established on legislation for 24 hours average $\left(50 \mu \mathrm{g} . \mathrm{m}^{-3}\right)$, although some hot-spots are visible where concentrations reach values of $90 \mu \mathrm{g} . \mathrm{m}^{-3}$ for this particular summer day. 



Figure 3: Comparison of $1.5 \mathrm{~m}$ high horizontal 24 hour average [PM10] fields in Athens domain, on $22^{\text {nd }}$ September 2008 for: a) baseline, b) PA2, c) PA3.

Figure 3 presents the simulation results for a specific summer day in Athens, for [PM10] levels, one of the most critical pollutants in this area.

Analysing the results presented in figure 3, it is clear that PA3 is the one that presents better results in the intervention area regarding [PM10]. Values as high as $130 \mu \mathrm{g} . \mathrm{m}^{-3}$ were obtained for all the situations, with a strong reduction in the intervention area for PA3.

Athens is the only city case in which an air quality monitoring station is located within the study area. Figure 4 presents a time series of simulated and measured [PM10] during the year of 2008. Observed air quality levels were acquired at the Aristotelous air quality monitoring station. The simulated values are from a specific cell of the domain which corresponds to the location of the referred air quality station.

In general, simulated values reasonably follow the trend of measured concentrations. However, some underestimation tendency was observed. Possible reasons are the lack of information relating background concentrations and local emission point sources, as well as the no consideration of particulate matter resuspension (only direct exhaust emissions were considered). It can be also inferred from the analysis of Figure 4 that both measured and simulated PM10 concentrations show several exceedances to the legislated limit value of $50 \mu \mathrm{g} \cdot \mathrm{m}^{-3}$. 




Figure 4: $\quad$ Comparison of measured and simulated [PM10] in the Aristotelous air quality station for the year 2008 (XY coordinates: $2800 \mathrm{~m}$; $2000 \mathrm{~m})$.
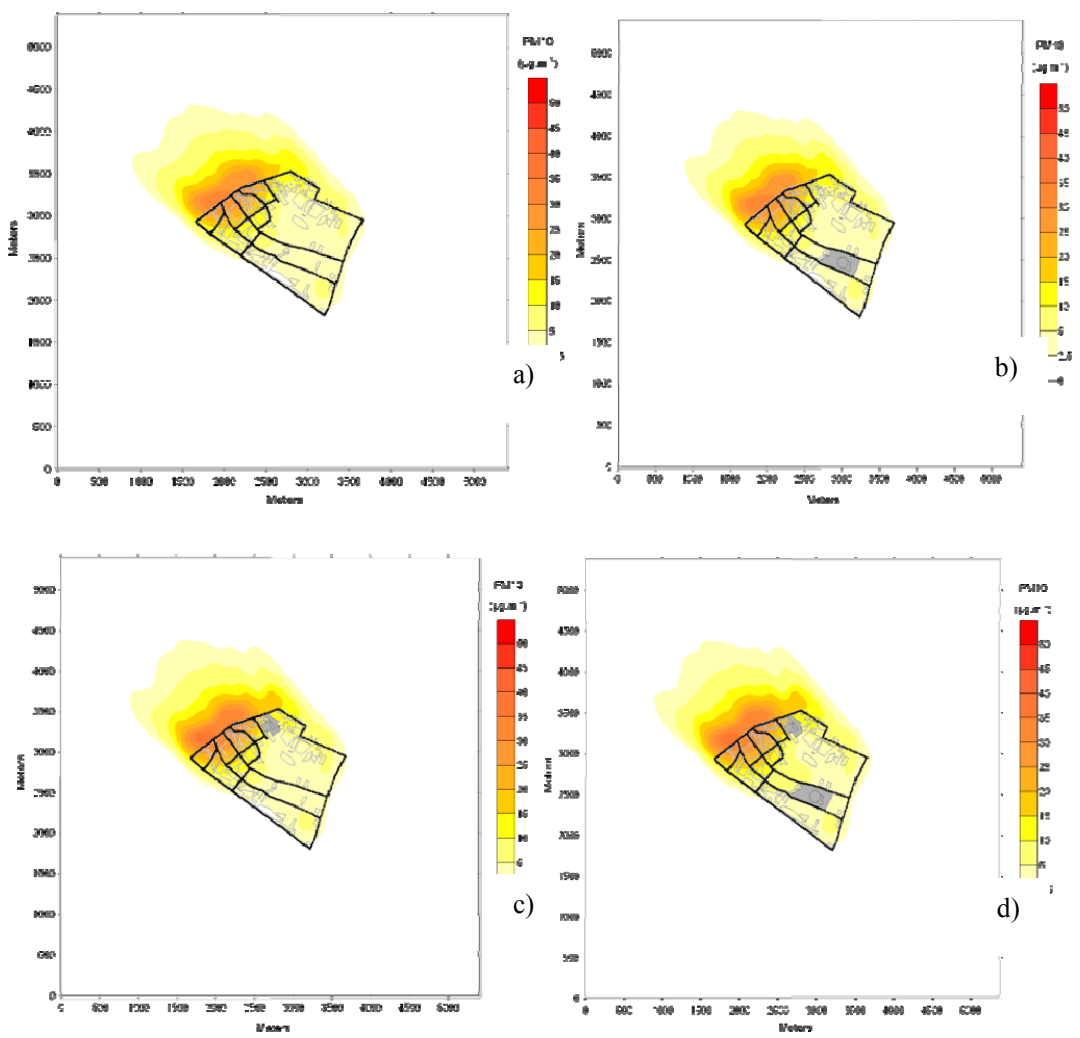

Figure 5: Comparison of $1.5 \mathrm{~m}$ high horizontal 24 hour average [PM10] fields in Gliwice domain, on $2^{\text {nd }}$ January 2008 for: a) baseline, b) PA1, c) PA2, d) PA3. 
In figure 5 the PM10 simulation results are presented for Gliwice study case on $2^{\text {nd }}$ January 2008 for baseline situation and PA1, PA2 and PA3.

Comparing the results obtained for the baseline situation and planning alternatives, no major differences in [PM10] are visible, showing that the implementation of the new buildings and the increase in traffic fluxes forecast in the nearby roads do not have a significant impact in [PM10].

In order to have a better understanding on the influence of the different alternatives on air quality, table 2 shows the maximum simulated concentrations of PM10, $\mathrm{CO}, \mathrm{NO}_{2}$ and $\mathrm{SO}_{2}$ in Helsinki, Athens and Gliwice during 2008. This value corresponds to the maximum concentration calculated by URBAIR for a height of 1.5 meters above ground.

From the analysis of the results shown in Table 1 it is possible to conclude that for Helsinki the planning alternatives do not have an influence in the maximum simulated concentrations despite the construction of new roads. Regarding Athens study case, PA2 will lead, according to the simulations, to an increase of the maximum concentrations for all the pollutants considered, while PA3 supports a decrease of the peak concentration when compared with the baseline situation. In Gliwice, baseline scenario and PA1 present the same results, while PA2 and PA3 have lower maximum values.

Table 1: Maximum simulated concentrations of PM10, $\mathrm{CO}, \mathrm{NO}_{2}$ and $\mathrm{SO}_{2}$ at 1.5 meters high for Helsinki, Athens and Gliwice in 2008.

\begin{tabular}{|c|c|c|c|c|}
\hline \multirow{2}{*}{ Study case } & \multirow{2}{*}{ Baseline } & \multicolumn{3}{|c|}{ Planning alternative } \\
\hline & & 1 & 2 & 3 \\
\hline \multicolumn{5}{|c|}{$\mathrm{PM} 10\left[\mu \mathrm{g} \cdot \mathrm{m}^{-3}\right]$} \\
\hline Helsinki & 227 & 227 & 227 & 227 \\
\hline Athens & 248 & - & 253 & 222 \\
\hline Gliwice & 37 & 37 & 42 & 42 \\
\hline \multicolumn{5}{|c|}{$\mathrm{CO}\left[\mu \mathrm{g} \cdot \mathrm{m}^{-3}\right]$} \\
\hline Helsinki & 1531 & 1531 & 1532 & 1532 \\
\hline Athens & 5045 & - & 5526 & 4995 \\
\hline Gliwice & 451 & 451 & 461 & 461 \\
\hline \multicolumn{5}{|c|}{$\mathrm{NO}_{2}\left[\mu \mathrm{g} \cdot \mathrm{m}^{-3}\right]$} \\
\hline Helsinki & 230 & 230 & 230 & 230 \\
\hline Athens & 382 & - & 388 & 370 \\
\hline Gliwice & 58 & 58 & 68 & 68 \\
\hline \multicolumn{5}{|c|}{$\mathrm{SO}_{2}\left[\mu \mathrm{g} \cdot \mathrm{m}^{-3}\right]$} \\
\hline Helsinki & 84 & 84 & 84 & 84 \\
\hline Athens & 236 & - & 240 & 228 \\
\hline Gliwice & 30 & 30 & 36 & 36 \\
\hline
\end{tabular}

Another analysis was made in terms of the number of exceedances to the limit value of simulated pollutants during the entire year of 2008 for a specific cell of the domain for each study case. This analysis is presented is Table 2. The selected computational cell in Athens and Gliwice corresponds to the location of 
the air quality station, although in the latter measurements are not available for 2008. In Helsinki, the selected cell corresponds to the centre of the domain.

Table 2: Number of exceedances to PM10, $\mathrm{CO}, \mathrm{NO}_{2}$ and $\mathrm{SO}_{2}$ in Helsinki, Athens and Gliwice during 2008.

\begin{tabular}{|c|c|c|c|c|c|}
\hline \multirow{2}{*}{ Study case } & \multirow{2}{*}{ Baseline } & \multicolumn{3}{|c|}{ Planning alternative } & \multirow{2}{*}{$\begin{array}{c}\text { Compliance with the } \\
\text { Directive? }\end{array}$} \\
\hline & & 1 & 2 & 3 & \\
\hline \multicolumn{6}{|c|}{ PM10 } \\
\hline Helsinki & 0 & 0 & 0 & 0 & $\mathrm{y}$ \\
\hline Athens & 122 & - & 122 & 96 & $\mathrm{n}$ \\
\hline Gliwice & 0 & 0 & 0 & 0 & $\mathrm{y}$ \\
\hline \multicolumn{6}{|c|}{$\mathrm{CO}$} \\
\hline Helsinki & 0 & 0 & 0 & 0 & $\mathrm{y}$ \\
\hline Athens & 0 & - & 0 & 0 & $\mathrm{y}$ \\
\hline Gliwice & 0 & 0 & 0 & 0 & $\mathrm{y}$ \\
\hline \multicolumn{6}{|c|}{$\mathrm{NO}_{2}$} \\
\hline Helsinki & 0 & 0 & 0 & 0 & $\mathrm{y}$ \\
\hline Athens & 5 & - & 5 & 3 & $\mathrm{y}$ \\
\hline Gliwice & 0 & 0 & 0 & 0 & $\mathrm{y}$ \\
\hline \multicolumn{6}{|r|}{ 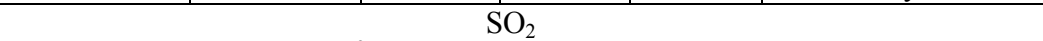 } \\
\hline Helsinki & 0 & 0 & 0 & 0 & $\mathrm{y}$ \\
\hline Athens & 0 & - & 0 & 0 & $\mathrm{y}$ \\
\hline Gliwice & 0 & 0 & 0 & 0 & $\mathrm{y}$ \\
\hline
\end{tabular}

With the analysis based on the selected cell for each study case, only for the pollutant PM10 in Athens study case were found exceedances in terms of the number permitted by the European legislation. For $\mathrm{NO}_{2}$ some exceedances were forecast but within the accomplishing criteria established in legislation. However, if the selected cell was in a different location, the situation could change and more exceedances might be found. Despite the number of exceedances is beyond the allowed number permitted by the legislation, in PA3 there is a reduction on their number for PM10.

With the analysis based on the selected cell for each study case, only in Athens study case and for PM10 were found exceedances to the limit value. Despite the number of exceedances is beyond the allowed number, PA3 can potentially lead to an improvement on the local air quality.

\section{Conclusions}

URBAIR applications allowed a comparative analysis between current situations and predefined planning alternatives in terms of the number of exceedances to air quality thresholds and other parameters established in European legislation. In general, it was concluded from the comparisons of simulated concentrations with 
measured data that URBAIR presents some underestimation tendency. Among the reasons for this behaviour the followings issues can be raised:

- Background concentrations and local emission point sources were not considered, due to lack of information;

- Except for Athens study case, average hourly traffic fluxes were calculated from annual values;

- Only exhaust emissions were considered (i.e., the contribution of particles resuspension was not taken into account);

- Road traffic emissions were estimated based on vehicles count and average speed. This methodology does not allow accounting for the emissions during traffic jams, which can be relevant, especially in Athens, during the peak hours;

- Also the contribution of natural events, which can be relevant in some air pollution episodes, was not considered.

Despite the small scale of the considered planning alternatives in terms of project dimension and the area of intervention, the results provide important information to urban planners and policy makers to choose the best planning solution according to quality of life standards pursuit by the local authorities.

\section{Acknowledgements}

The authors would like to acknowledge the financial support of the BRIDGE Project by the European Commission under the $7^{\text {th }}$ Framework Programme, and the Portuguese Ministry of Science, Technology and Higher Education, through the Foundation for Science and Technology (FCT), for the Post-Doc grant of J. H. Amorim (SFRH/BPD/48121/2008) and for the financial support of project INSPIRAR (PTDC/AAC-AMB/103895/2008), supported in the scope of the Competitiveness Factors Thematic Operational Programme (COMPETE) of the Community Support Framework III and by the European Community Fund FEDER.

\section{References}

[1] Borrego, C., Lopes, M., Valente, V., Neuparth, N., Martins, P., Amorim, J.H., Costa, A.M., Silva, J., Martins, H., Tavares, R., Nunes, T., Miranda, A.I., Cascão, P. \& Ribeiro, I., The importance of urban planning on air quality and human health (Chapter 2). Urban Planning in the 21st Century, eds. D.S. Graber \& K.A. Birmingham, Nova Science Publishers Inc., 2009.

[2] Martins, H., Miranda, A. \& Borrego, C., Atmospheric modelling under urban land use changes: meteorological and air quality consequences. 31st NATO/SPS International Technical Meeting on Air Pollution Modelling and its Application, 27 Sept-1 Oct., Torino, Italy. 2010.

[3] Amorim, J.H., Lopes, M., Borrego, C., Tavares, R. \& Miranda, A.I., Air quality modelling as a tool for sustainable urban traffic management. Air Pollution XVIII. 21-23 June, Kos, 3-14. Greece. WIT Press. 2010. 
[4] European Environment Agency. Towards a resource-efficient transport system. TERM 2009: indicators tracking transport and environment in the European Union. EEA Report, No 2. 2010.

[5] ETC/ACC 2009a: European exchange of monitoring information and state of the air quality in 2007. ETC/ACC Technical Paper 2009/3.

[6] Borrego, C., Tchepel, O., Costa. A., Amorim, J. \& Miranda, A., Emission and dispersion modelling of Lisbon air quality at local scale. Atmospheric Environment, 37, 5197-5205, 2003.

[7] Martins, A., Cerqueira, M., Ferreira, F., Borrego, C. \& Amorim, J.H., Lisbon air quality - evaluating traffic hot-spots, International Journal of Environment and Pollution - Vol. 39, Issue 3/4, 306-320, 2009.

[8] Borrego, C., Tchepel, O., Salmin, L, Amorim, J.H., Costa, A.M. \& Janko, J., Integrated modelling of road traffic emissions: application to Lisbon air quality management, Cybernet. Sys.: An International Journal 35 (5-6), 535-548, 2004.

[9] Borrego, C., Martins, J.M, Lemos, S. \& Guerreiro, C., Second generation Gaussian dispersion model: the POLARIS model. International Journal of Environment and Pollution - Vol. 8, No.3/4/5/6 pp. 789 - 795, 1997.

[10] Bridge Newsletter. Issue 2 may 2010.

[11] http://www.bridgefp7.eu/images/pdf/211345_001_DM_NKUA_1_0_2nd_ Newsletter.pdf 